\title{
Economic announcements and the 10-year U.S. Treasury: Surprising findings without the surprise component.
}

\author{
Stavros Degiannakis ${ }^{1}$, George Filis ${ }^{2}$ and Stefanos Tsemperlidis ${ }^{1{ }^{*}}$ \\ ${ }^{1}$ Department of Economics and Regional Development, Panteion University of Social \\ and Political Sciences, 136 Syggrou Avenue, 17671, Greece. \\ ${ }^{2}$ Department of Accounting, Finance and Economics, Bournemouth University, 89 \\ Holdenhurst Road, BH8 8EB, Bournemouth, UK. \\ *Corresponding author's email: steftsemp@panteion.gr
}

\begin{abstract}
In the current study we identify the announcements that trigger substantial changes in the behavior of the 10-year US Treasury market, without using the surprise component and, therefore, expectational data. We use a novel model-free approach based on extreme market movements related to price returns, volatility and traded volumes. Our findings corroborate those of previous studies, which were based on expectational data. More importantly, though, we identify two additional announcements (Oil Inventories and the Mortgage Applications), which have not been previously reported. These findings are primarily important to financial analysts and investors.
\end{abstract}

Key words: US Treasury market, economic announcements, event studies. JEL: G12, G14 


\section{Introduction}

Economic announcements are recognized as major determinants of asset prices formation. However, the differentiation between relevant and irrelevant economic news with regards to a specific asset class, the measurement of the announcements' impact on the market dynamics and the extent to which market movements can be attributed to new information, remain issues under examination for more than three decades (important contributions include, Cuttler et al., 1989; Engle and Victor, 1993; Fleming and Remolona, 1997; Bollerslev et al., 2000; Evans, 2011, Monticini et al., 2011; among others).

A key feature of the aforementioned studies is the use of the surprise component, which is defined as the difference between the expected and the actual number released during an announcement. This is theoretically explained by the hypothesis that a market should respond not only to the event itself but to the unexpected part of the information released during an event (Fleming and Remolona, 1997; Balduzzi et al., 2001). Various regression models of returns, volatility or volume on surprises have been used for tracing importance, size or speed of impact of announcements on markets.

It is well documented that the US Treasury bond market is considered to react strongly to the US economic releases, although the specific announcements vary among studies and time period. Largely, the most important announcements are associated with real output, employment, prices and monetary policy (see, inter alia, Beechey and Wright, 2009; Fleming and Remolona, 1997; Baltuzzi et al., 2001; Kearney, 2001). Recently, though, there is evidence of increasing importance of advance readings of GDP, consumers and investors' sentiment and nowcasting indicators in regard to price variations (Bollerslev et al., 2000).

Although the use of the surprise component is dominant in the relevant literature, there are drawbacks in measuring market expectations. The surprise component is based on expectational data (surveys), which in turn, contain errors due to the lag between expectation data and released data or/and due to poor measurement (Rigobon and Sack, 2008).

Our study, which is based on a rich, tick-by-tick, dataset, shows that it is feasible to identify important announcements for the 10-year Treasury bond without using the surprise component and therefore expectational data which are sometimes expensive and sometimes dubious. Interestingly enough, our findings confirm those of previous studies, which were based on expectational data; however, we should highlight that two additional announcements (Oil Inventories and the Mortgage Applications), which have not been previously reported, are also identified, demonstrating the validity and added-value of our approach.

The remaining of the paper is structured as follows. Section 2 describes the data, Section 3 details our model-free approach, Section 4 discusses the findings and Section 5 concludes the study. 


\section{Data}

We use a very rich dataset which includes 120 million tick-by-tick observations of prices and volume for the 10-year US T-bond collected from Tickdata (4 January, 2012 - 31 December, 2014: 772 trading days). Furthermore, during this time span there are approximately 2,500 announcement releases related to the US economic indicators. Based on the tick-by-tick data we construct the following minute-byminute measures:

1. $r_{m}=\log \left(c_{m} / c_{m-1}\right) \times 100$ is the log-returns per minute, where $c_{m}$ is the last tick price at minute $m$.

2. $v_{m}$ : volume of trade per minute.

3. $y_{m}=\left(h_{m}-l_{m}\right)$ is a range based volatility of price per minute, where $h_{m}$ and $l_{m}$ are the highest and lowest transaction prices during any particular minute.

The transformed dataset includes approximately one million minute-by-minute observations. Table 1 and Figure 1 present the descriptive statistics and the kernel density estimate of the distribution of the variables under investigation, respectively. Evidently, the three measures present large variations and extreme values, which we test if they are associated with economics announcements.

\section{[TABLE 1 HERE] [FIGURE 1 HERE]}

\section{Methodology}

The proposed model-free approach is based on the identification of extreme values of the three aforementioned measures and how these are linked with economic announcements. Our approach is predicated upon the premise that important announcements should be more frequently associated with abrupt changes in the three measures. Abnormal events such as price volatility jumps or daily excess returns are widely used in event studies to associate assets dynamics with announcements (Fleming and Remolona, 1999; Dungey et al., 2009; Rosa, 2016).

Our approach is as follows:

\section{i. Identify extreme values}

For each measure we employ a criterion of extremity. For returns, we follow Fleming and Remolona (1997), with extreme returns $\left(r_{m}^{\text {ext }}\right)$ being identified as $r_{m}>0.2 \%$ or $r_{m}<-0.2 \%$, at any given minute ${ }^{1}$. Extreme volume $\left(v_{m}^{e x t}\right)$, i.e. trading activity, is regarded as the maximum daily $v_{m}$ for every trading week and expresses the $0.0149 \%$ upper quantile point of the empirical distribution. Finally, extreme volatility $\left(y_{m}^{e x t}\right)$ is regarded the $y_{m}$ that is greater than or equal 10 times the median of the sample's volatility $\left(\widetilde{y}_{m}\right)^{2,3}$. We then identify the days and times of

\footnotetext{
${ }^{1}$ The $r_{m}= \pm 0.2 \%$ express the $0.0035 \%$ lower and upper quantile points of the empirical distribution.

${ }^{2}$ The $10 \tilde{y}_{m}$ expresses the $0.0377 \%$ upper quantile point of the empirical distribution.
} 
extreme values occurrence. The period under investigation contains 73 occurrences of $r_{m}^{\text {ext }}, 157$ of $v_{m}^{\text {ext }}$ and 397 of $y_{m}^{\text {ext }}$.

ii. Identify announcements

For each day that contains extreme values we trace which announcements $(i)$ are released, using the monthly Economic Policy indicators calendar of the years 20122014 (US Department of Treasury). During each month there are between 66 and 76 scheduled announcements of weekly, monthly, quarterly or other periodicity $(j)$ US economic indicators. The earlier recorded announcement is the Monster Employment Index (monthly) at 6:00 and the latest recorded announcement is the Auto Sales (monthly) at 17:00 (EST time). The 90\% of the announcements are released between 7:00-11:00 (EST time).

iii. Identify important announcements

For each of the three measures we calculate the frequency of announcements' occurrence $\left(f_{i, j}\right)$ found in $(i i)$ :

$$
f_{i, j}=\frac{n_{i, j}}{T}
$$

where $n_{i, j}$ is the number of occurrence of announcement $i$ with periodicity $j$ (weekly, monthly, quarterly or other) in extreme events and $T$ is the total number of extreme events.

We calculate the mean frequency of occurrence $\left(F_{j}\right)$ in extreme events for the different periodicities:

$$
F_{j}=\frac{\sum f_{i, j}}{k}
$$

where $k$ is the number of announcements at its particular frequency. So, if $f_{i, j}>F_{j}$ then the announcement is considered to be important for the formation of the 10-year Treasury bond dynamics.

\section{$i v$. Identify most important announcements}

The above steps provide three sets of announcements. By keeping only the common announcements of these sets we extract a Most Important Announcements List for the US bond market.

\section{Results}

Tables 2-4 present the three sets of announcements in regard to the three measures and Table 5 presents the merged Most Important Announcements list, categorized by their content.

Similarly with other studies, we find that about $40 \%$ of the total announcements are associated with extreme trading volume, followed by the $33 \%$ which are linked with extreme volatility and $20 \%$ with extreme returns.

Our results are highly consistent in comparison to other studies that employ the surprise-depended models (e.g. Fleming and Remolona, 1997; Balduzzi et al., 2001, Andersen et al., 2007), showing that announcements related to advance readings of GDP, consumers' sentiment and employment, among others, trigger extreme movements in all three measures. More importantly, though, we report two additional announcements, Oil Inventories and Mortgage Applications, as being important for

\footnotetext{
${ }^{3}$ We have also experimented with other criteria of extremity (e.g. $r_{m}>0.1 \%$ or $r_{m}<-0.1 \%$ and $r_{m}>0.3 \%$ or $r_{m}<-0.3 \%$, the five largest daily $v_{m}$ for every month and $\left.y_{m}>5(15) \times \tilde{y}_{m}\right)$ and we obtained qualitatively similar results.
} 
the US bond market. The importance of these announcements has not being previously documented. We maintain that these new findings hold true as (i) the level of inventories are expected to exercise an impact on bond prices, via their effect on oil price speculation and, in turn, oil prices (see, Fattouh et al., 2013) and (ii) Mortgage Applications is a measure of demand for real estate property, a parameter that affects the demand for fixed-income assets.

[TABLE 2 HERE]
[TABLE 3 HERE]
[TABLE 4 HERE]
[TABLE 5 HERE]

\section{Conclusion}

In the examination market-information interaction it is vital to evaluate which information affects an asset market. Our model-free approach is capable of identifying the most relevant announcements without using expectational data. We show that an investigation of the relevant announcements based on the extreme market movements, in terms of the first two moments, as well as, the trading activity, may be used to substitute, crosscheck or complement the standard methods based on the surprise component. Our results may be further investigated for other asset markets. These findings have important implications to investors and financial analysts, who do not necessarily have access to the expectational data.

\section{References}

Andersen, T., Bollerslev, T., Diebold, F., \& Vega, C. (2007). Real-time price discovery in global stock, bond and foreign exchange markets. Journal of International Economics, 73 (2), 251-277.

Balduzzi, P., Elton, E., \& Green, T. (2001). Economic News and Bond Prices: Evidence from the U.S. Treasury Market. Journal of Financial and Quantitative Analysis, 36 (4), 523-543.

Beechey, M., \& Wright, J. (2009). The high-frequency impact of news on long-term yields and forward rates: Is it real? Journal of Monetary Economics, 56 (4), 535544.

Bollerslev, T., Cai, J., \& Song, F. (2000). Intraday periodicity, long memory volatility, and macroeconomic announcement effects in the US Treasury bond market. Journal of Empirical Finance, 7 (1), 37-55.

Cuttler, D., Poterba, J., \& Summers, L. (1989). What Moves Stock Prices? The Journal of Portfolio Management, 15 (3), 4-12.

Dungey, M., McKenzie, M., \& Vanes, L. (2009). Empirical evidence on jumps in the term structure of the US Treasury Market. Journal of Empirical Finance, 16 (3), 430-445.

Engle, R., \& Victor, K. (1993). Measuring and testing the impact of news on volatility. The Journal of Finance, 48 (5), 1749-1778.

Evans, K. (2011). Intraday jumps and US macroeconomic news announcements. Journal of Banking \& Finance, 35 (10), 2511-2527

Fattouh, B., Kilian, L., \& Mahadeva, L. (2013). The role of speculation in oil markets: What have we learned so far?. The Energy Journal, 7-33.

Fleming, M. J., \& Remolona, E. M. (1997). What Moves the Bond Market? Economic Policy Review, 3 (4), 31-50. 
Fleming, M., \& Remolona, E. (1999). Price Formation and Liquidity in the U.S. Treasury Market: The Response to Public Information. The Journal of Finance, 54 (5), 1901-1915.

Kearney A.A. (2001). A note on modeling the impact of economic announcements on interest rates. Economics Letters, 71, 83-89.

Monticini, A., Peel, D., \& Vaciago, G. (2011). The impact of ECB and FED announcements on the Euro interest rates. Economics Letters, 113(2), 139-142.

Rigobon, R., \& Sack, B. (2008). Noisy macroeconomic announcements, monetary policy, and asset prices. In e. John Y. Campbell, Asset Prices and Monetary Policy. National Bureau of Economic Research, University of Chicago Press.

Rosa, C. (2016). Walking on thin ice: Market quality around FOMC announcements. Economics Letters, 138, 5-8 


\section{Figures \& Tables}

Figure 1. Kernel density graphs of log-returns, range volatility and volume of trade.

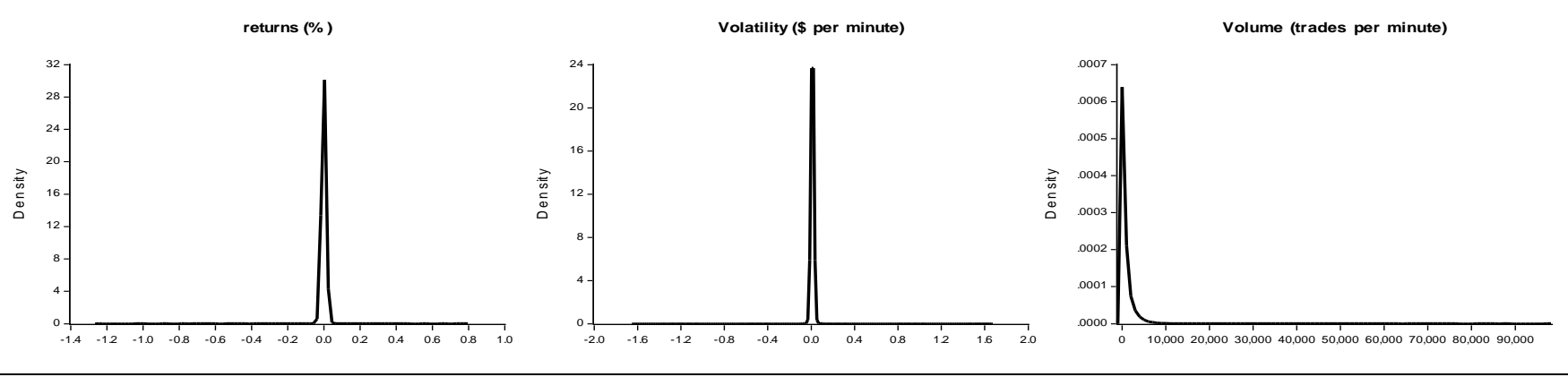


Table 1. Descriptive statistics log-returns, range volatility and volume of trade

\begin{tabular}{lrrr}
\hline & \multicolumn{1}{c}{$r_{m}$} & \multicolumn{1}{c}{$v_{m}$} & $y_{m}$ \\
\cline { 2 - 4 } Mean & -0.0001 & 745.4920 & 0.0118 \\
Maximum & 0.0000 & 153.0000 & 0.0156 \\
Minimum & 0.7752 & 97382.0000 & 1.5312 \\
Std. Dev. & -1.2445 & 0.0000 & 0.0000 \\
\hline $\begin{array}{l}\text { Average min-by-min } \\
\text { obs per day }\end{array}$ & 0.0107 & 1615.0401 & 0.0141 \\
$\begin{array}{l}\text { Average tick-by-tick } \\
\text { obs per day }\end{array}$ & & 1360 & \\
\hline
\end{tabular}

\begin{tabular}{|c|c|c|}
\hline Periodicity & Announcement & \% appearance \\
\hline \multirow{2}{*}{ Weekly } & Oil inventories & 17.8 \\
\hline & Mortgage Applications & 24.7 \\
\hline \multirow{10}{*}{ Monthly } & NAR PH Sales Index & 9.6 \\
\hline & Monster employment index & 16.4 \\
\hline & Employment Situation & 34.2 \\
\hline & Factory orders & 9.6 \\
\hline & Consumer Credit & 11.0 \\
\hline & NY Fed Mfg survey & 8.2 \\
\hline & Personal income & 11.0 \\
\hline & Construction & 8.2 \\
\hline & International Trade & 8.2 \\
\hline & GDP (estimation) & 11.0 \\
\hline Quarterly & Current account & 4.1 \\
\hline 8 times/year & FOMC & 11.0 \\
\hline Twice/month & Consumers Sentiment* & 15.1 \\
\hline \multicolumn{3}{|c|}{$\begin{array}{l}\text { Note: \% appearance denotes } f_{i, j} \times 100 . \text { The average frequencies } F_{j} \times \\
100 \text { are: } F_{w}=16.7 \%, F_{m}=6.8 \%, F_{q}=2.7 \%, F_{8}=8.2 \% \text {, where w=weekly, } \\
\mathrm{m}=\text { monthly, q=quarterly and } 8=8 \text { times per year. } \\
\text { *Consumers Sentiment is the only announcement with this periodicity, hence } \\
\text { the } F_{j} \text { is the same as its } f_{i, j} \text {. We include it in our results due to its high } \\
\text { frequency of occurrence in extreme events. }\end{array}$} \\
\hline
\end{tabular}




\begin{tabular}{|c|c|c|}
\hline Periodicity & Announcement & \% appearance \\
\hline \multirow{2}{*}{ Weekly } & Oil inventories & 29.47 \\
\hline & Mortgage Applications & 40.05 \\
\hline \multirow{16}{*}{ Monthly } & CPI & 8.31 \\
\hline & Housing Starts & 7.30 \\
\hline & Phil. Fed. Survey & 5.79 \\
\hline & Monster employment index & 12.09 \\
\hline & Employment Situation & 19.65 \\
\hline & Factory orders & 6.80 \\
\hline & Consumer Credit & 8.31 \\
\hline & Import prices & 6.05 \\
\hline & NY Fed Mfg survey & 8.82 \\
\hline & PPI & 11.34 \\
\hline & ADP Employment Index & 7.81 \\
\hline & Monthly chain sales & 5.54 \\
\hline & Retail sales & 11.84 \\
\hline & Business Inventories & 11.84 \\
\hline & HelpWant online & 6.55 \\
\hline & GDP (est) & 8.06 \\
\hline Quarterly & Current account & 6.55 \\
\hline 8 times/year & FOMC meeting & 18.89 \\
\hline Twice/month & Consumers Sentiment* & 7.05 \\
\hline \multicolumn{3}{|c|}{$\begin{array}{l}\text { Note: } \% \text { appearance denotes } f_{i, j} \times 100 . \text { The average frequencies } F_{j} \times \\
100 \text { are: } F_{w}=22.7 \%, F_{m}=5.23 \%, F_{q}=2.42 \%, \quad F_{8}=14.11 \% \text {, where } \\
\text { w=weekly, m=monthly, q=quarterly and } 8=8 \text { times per year. } \\
\text { * Consumers Sentiment is the only announcement with this periodicity, hence } \\
\text { the } F_{j} \text { is the same as its } f_{i, j} \text {. We include it in our results due to its high } \\
\text { frequency of occurrence in extreme events. }\end{array}$} \\
\hline
\end{tabular}


Table 4. Extreme volume: important announcements

\begin{tabular}{|c|c|c|}
\hline Periodicity & Announcement & \% appearance \\
\hline \multirow{4}{*}{ Weekly } & UI claims & 26.8 \\
\hline & Consumer Comfort index & 26.8 \\
\hline & Oil inventories & 28.7 \\
\hline & Mortgage Applications & 23.6 \\
\hline \multirow{19}{*}{ Monthly } & CPI & 6.4 \\
\hline & Housing Starts & 8.3 \\
\hline & Phil. Fed. Survey & 8.3 \\
\hline & Advance Durable Orders & 5.1 \\
\hline & Monster employment index & 8.9 \\
\hline & Employment Situation & 18.5 \\
\hline & Factory orders & 5.7 \\
\hline & Consumer Credit & 7.0 \\
\hline & Wholesale trade & 7.0 \\
\hline & ISM-Chicago index & 6.4 \\
\hline & Import prices & 7.0 \\
\hline & NY Fed Mfg survey & 5.7 \\
\hline & PPI & 6.4 \\
\hline & NAHB Housing index & 5.7 \\
\hline & Personal income & 7.0 \\
\hline & Retail sales & 7.0 \\
\hline & Business Inventories & 7.0 \\
\hline & International Trade & 7.0 \\
\hline & GDP (estimation) & 5.7 \\
\hline \multirow{3}{*}{ Quarterly } & Current account & 3.8 \\
\hline & ECI & 1.3 \\
\hline & Fed FoF & 1.3 \\
\hline 8 times/year & FOMC meeting & 5.7 \\
\hline Twice/month & Consumers Sentiment* & 14.0 \\
\hline \multicolumn{3}{|c|}{$\begin{array}{l}\text { Note: } \% \text { appearance denotes } f_{i, j} \times 100 . \text { The average frequencies } F_{j} \times 100 \text { are: } \\
F_{w}=22.3 \%, F_{m}=4.80 \%, F_{q}=1.12 \%, F_{8}=4.51 \% \text {, where w=weekly, m=monthly, } \\
\text { q=quarterly and } 8=8 \text { times per year. } \\
\text { *Consumers Sentiment is the only announcement with this periodicity, hence the } F_{j} \text { is } \\
\text { the same as its } f_{i, j} \text {. We include it in our results due to its high frequency of occurrence } \\
\text { in extreme events. }\end{array}$} \\
\hline
\end{tabular}

Table 5. Most Important Announcements for the 10y T-Bond

\begin{tabular}{ccc}
\hline $\begin{array}{c}\text { Monetary- } \\
\text { Financial }\end{array}$ & $\begin{array}{c}\text { Production- } \\
\text { Economic Activity }\end{array}$ & $\begin{array}{c}\text { Expectations- } \\
\text { Confidence }\end{array}$ \\
\hline Oil inventories & Employment Situation & NY Fed Mfg survey \\
Mortgage Applications & Factory orders & Consumers Sentiment \\
Consumer Credit & GDP (estimation) & \\
FOMC & Monster employment index & \\
\hline
\end{tabular}

